\title{
Voluntary disclosure of contributions: an experimental study on nonmandatory approaches for improving public good provision
}

\author{
Ursula W. Kreitmair ${ }^{1}$
}

\begin{abstract}
There has been an increasing interest in nonpecuniary measures to encourage prosocial behavior. Among these is the use of social comparison, or social information. Although successful in promoting, for instance, greater resource conservation, studies of this measure have so far relied on the assumption of the availability of social information. In situations in which information is costly to collect and disseminate, alternative mechanisms must be considered. This study explores the use of voluntary disclosure to provide social information in a linear public goods game in a lab experiment. It finds that individuals tend to disclose their contribution information when given the option, suggesting that voluntarily disclosed social information remains a possible policy option when the cost of information collection is high. In addition, voluntarily revealed contributions are significantly higher than contributions under mandated disclosure, leading to greater cooperation in the voluntary disclosure treatments under certain circumstances. Finally, evidence is provided that voluntary disclosure may be helpful in attenuating the boomerang effect, i.e., when high contributors reduce their contributions in response to social information.
\end{abstract}

Key Words: behavioral information; cooperation; experiment; public goods; social comparison; social information; social norms; voluntary disclosure

\section{INTRODUCTION}

A growing literature explores the use of nonpecuniary measures to encourage welfare-enhancing behavior (see, for example, Thaler and Sunstein 2008 or Johnson et al. 2012). One strand of this literature explores the impact of "descriptive norms" (Cialdini et al. 1990) or "social information" (Croson and Shang 2008, Shang and Croson 2009) on prosocial behavior (McDonald and Crandall 2015). In other words, they examine the impact on behavior of individuals being provided with information on how others behave in similar circumstances. These descriptive norms have been used to study and promote prosocial behavior in a number of different environmental applications, such as increased curbside recycling, reuse of hotel towels, natural resource conservation, household energy conservation, and household water conservation (see Schultz 1999, Cialdini et al. 2006, Goldstein et al. 2008, Allcott 2011, Ferraro and Price 2013). This literature indicates that descriptive norms can be an effective means of encouraging prosocial behavior although this is dependent on the characteristics of the target population (Bao and Ho 2015).

Given that large-scale policy application of these "informational nudges" is a recent phenomenon, much remains to be researched. One such area that has yet to receive much attention is the voluntary disclosure of behavioral information. Often the information necessary for providing descriptive norms is not publicly available or must be compiled at high cost. For instance, consider the difficulty in assessing the precedence and distribution of illegal behavior, such as the theft of petrified wood from Arizona's Petrified Forest National Park (Cialdini et al. 2006). In these scenarios, providing social information might be difficult without voluntary disclosure of behavior. However, the impact of voluntarily provided behavioral information on prosocial behavior has not been studied systematically. This study seeks to address this gap by using a laboratory experiment to explore the voluntary disclosure of social information in a linear public goods game in which participants must decide how many tokens to contribute toward a group fund. This is a direct measure of prosocial behavior. In particular, the experiment utilizes four different information treatments: (1) no disclosure, in which individuals receive only aggregate information of group contributions; (2) mandatory disclosure, in which individuals receive information on every group member's contributions; (3) voluntary simultaneous to contribution, in which individuals may voluntarily disclose their contribution information; and (4) voluntary prior to contribution, in which individuals are notified about how many individuals have chosen to reveal their contributions before making their contribution decision. These treatments are used to examine the following questions: (1) With what frequency do individuals choose, when given the chance, to reveal to their group members their contributions to a public good? (2) Does the opportunity to voluntarily reveal contributions improve cooperation in comparison to scenarios with only group level information and with mandated disclosure of contributions? (3) To what extent is this effect driven by moral motivations as opposed to the ability to encourage reciprocal behavior from group members?

\section{SOCIAL INFORMATION}

The study focuses on the impact of social information on behavior in social dilemmas. Social dilemmas have been studied extensively in laboratory and field experiments. One way to model these dilemmas is using a linear public goods game. Consider the following (notation based on Isaac et al. 1994): In a group of size $N$ each individual receives an endowment of $Z$. They choose to contribute any amount, $m_{i}$, to a group fund, i.e., the public good. The payoffs from this group fund depend on the contributions by all group members (i.e., $\Sigma m_{i}$ ), and the payoff to each individual from the group fund is an equal share of total contributions multiplied by a rate of return multiplier $G$. If $m_{i}<Z$, the remainder $\left(Z-m_{i}\right)$ is transferred to the individual's private fund with a rate of return of $p$. Therefore, an individual's payoff function is: 


$$
\pi_{i}=p_{i}\left(Z_{i}-m_{i}\right)+G / N\left(m_{i}+\sum_{j, j \neq i}^{N} m_{j}\right)
$$

This payoff function reflects a social dilemma setting when $p>$ $G / N$ and $G>p$, which implies that it is rational, but not socially optimal, for individuals to transfer their endowment to the private fund. A concept that is often used to capture the relationship between $p$ and $G / N$ is the marginal per capita return (henceforth MPCR) on investment to the public good (Isaac et al. 1984). To capture incentives surrounding social dilemmas, the MPCR, which is $G / p N$, is less than one. Accordingly, the Nash equilibrium prediction is zero contributions to the public good.

Although the experimental literature on public goods games is extensive (see Ledyard 1995, Zelmer 2003, and Chaudhuri 2011 for reviews of broad experimental findings), few lab experiments explicitly test the impact of social information, operationalized here as individual-level contribution information. Sell and Wilson (1991), Weimann (1994), Wilson and Sell (1997), and Croson (2001) contrast treatments with information on aggregate group contributions with full social information at the individual level, meaning that after each decision round subjects are informed about how much each individual contributed. The results are mixed. Sell and Wilson (1991) found that contributions to the public good increase significantly; Weimann (1994) and Croson (2001) found no significant difference; and Wilson and Sell (1997) found that individual-level social information reduces contributions. This divergence may, in part, be related to Weimann including information on earnings as well as information on contributions, which may trigger less cooperative tendencies in participants (Bigoni and Suetens 2012). In line with Bigoni and Suetens, other lab experiments have highlighted the importance of selective presentation of social information. Clark (2002), for instance, provided subjects with information on the highest contribution each round, and Jones and McKee (2004) explored whether relative information, i.e., how the subject ranks with respect to contributions in the group, improves cooperation. Croson and Shang $(2008,2013)$ and Shang and Croson (2009) explored these effects in the field. Broadly, these studies found that presenting subjects with information on the highest contribution increases contribution rates if the difference between the subject's contribution and highest contribution is not too large. Likewise, information on the lowest contribution depresses contributions, suggesting convergence behavior toward the observed contribution level. This is the social comparison effect.

Field studies corroborate findings by Croson and Shang: In field experiments in which the underlying game structure may be described as an environmental social dilemma (see, for example, Schultz 1999, Cialdini et al. 2006, Goldstein et al. 2008, Allcott 2011, Ayres et al. 2013, Ferraro and Price 2013), individuals are swayed by social information. For instance, in the study by Ferraro and Price (2013), households that were presented with information on mean household water consumption, as well as technical advice on how to conserve water, reduced their water usage by more than households without this social comparison. In studies on household electricity use, Schultz et al. (2007) and Fischer (2008) corroborated this, but also found that behavior converges toward the mean. In other words, social comparison affects individuals differently, i.e., high consumers of electricity reduce their usage, but low electricity users increase their consumption. This increase in consumption, also called the boomerang effect (Schultz et al. 2007), can diminish the positive influence of social information depending on the composition of the group (Ostrom 2003, Bao and Ho 2015) and the information that is displayed. To avoid the boomerang effect, one might provide individuals with praise for prosocial behavior that exceeds the displayed social information (Schultz et al. 2007).

An alternative method to attenuate the boomerang effect is to increase the availability of information about relatively high contributions (Shang and Croson 2009) by allowing individuals to volunteer their contribution information. Voluntary disclosure of contribution information will result in the visible contribution average being higher than the actual mean of contributions: if (1) individuals choose to make their contributions public, and (2) public contributions are higher than hidden contributions. To see why this might be the case, consider the following behavioral model: Levitt and List (2007) included a moral component to explain behavior in differing contexts. In this model, utility is derived from pecuniary wealth $(W)$ and moral behavior $(M)$. These in turn are functions of the action taken $(a)$, the financial externality imposed on others $(v)$, the strength of social norms disproving of said action $(n)$, and the scrutiny under which the action is placed $(s)$. As $v$ increases, financial gain increases, given that more of the cost of engaging in $a$ is externalized. However, $M$ is negatively related to $v$, meaning that with greater financial externalities comes greater guilt in engaging in $a$. This alone may not be sufficient to sway behavior toward abstaining from engaging in $a$ to the extent which would be optimal to maximize $W$; however, as social norms and scrutiny of one's actions increase, individuals mav alter their behavior.

$$
U_{i}(a, v, n, s)=M_{i}(a, v, n, s)+W_{i}(a, v)
$$

For this study, $a$ constitutes contributions toward the public good. On the basis of this preference structure and $M$ being positively correlated with $a$, the following conjectures arise:

\section{C1. Individuals will voluntarily disclose contributions with significant frequency}

If individuals can choose to reveal their contributions, $s$ becomes endogenously determined. The decision to disclose contributions is therefore a decision to increase $s$, which increases the impact moral considerations have on behavior. Disclosure is therefore a costly action that can be interpreted as a credible signal of the willingness to cooperate. This might then be used as a means of avoiding the assurance problem (Runge 1984, Isaac et al. 1989), in which individuals wish to contribute only if others do so as well. The experimental literature on endogenous institutional choice corroborates this conjecture by finding that subjects often self-select into various governance institutions that restrict viable contribution choices, which ultimately leads to greater contributions overall (see, for example, Botelho et al. 2005, Kroll et al. 2007, Kosfeld et al. 2009, Sutter et al. 2010, Hamman et al. 2011). 


\section{C2. Voluntarily revealed contributions will be higher than hidden contributions}

Given a higher value of scrutiny $s$, when contributions are public, the relative impact of $M$ increases, leading to individuals choosing to contribute greater amounts. However, individuals need not derive utility from moral actions to engage in them. If a selfregarding and financially motivated actor suspects that others might be motivated by contribution norms, improving this social norm by increasing contributions may be profitable and hence rational (Kreps et al. 1982). This suggests that: (1) contributions in the mandatory treatment and disclosed contributions in the voluntary treatments will be higher than contributions in the no disclosure treatment; (2) public contributions in the voluntary treatments will be higher than hidden contributions in the voluntary treatments; and (3) average public contributions in the voluntary treatments will be higher than average contributions in the mandatory treatment, because in the voluntary treatments individuals who are not sufficiently motivated by increased scrutiny, but believe that group members might respond negatively to free riding by others, can self-select into hiding their low contribution.

\section{C3. Voluntary disclosure leads to greater contributions at the group level}

If $\mathrm{C} 1$ and $\mathrm{C} 2$ occur at sufficiently high levels, then, given the evidence that individuals converge on the mean (see discussion above), voluntary disclosure will lead to greater contributions than in both the no disclosure and mandatory disclosure treatments.

\section{C4. Greater social information, i.e., information on more individuals' contributions, leads to more contributions at the group level}

If $\mathrm{C} 1$ holds, then, as more individuals face a high value of $s$, group contributions increase. Thus, contributions in the no disclosure treatment will be lower than in all other treatments, given nonzero disclosure in the voluntary treatments.

C5. Increased ability to signal leads to higher group contributions This relates directly to the extent to which low contributions are related to the assurance problem, as opposed to free-riding preferences, i.e., high relative weight of $W$ as compared to $M$. If the assurance problem motivates behavior, then individuals knowing how many others have chosen to make contributions public (see $\mathrm{C} 1$ and $\mathrm{C} 2$ ) before making their contributions will lead to increased contributions. In this case, contributions in the voluntary prior to contribution treatment will be higher than contributions in the voluntary simultaneous to contribution treatment, in which signaling may occur but must be done over two periods and is hence less likely to be effective. Therefore, the difference in contributions between these two treatments measures the extent to which contributions are driven by the ability to encourage reciprocal behavior from group members as opposed to the ability to self-select into a disclosure institution.

Although voluntary disclosure may arguably lead to greater cooperation, there is very little, if any, research directly exploring this effect in linear public goods games. Andreoni and Petrie (2004) explored the impact of identifiability in connection with behavioral information. In their optional-reporting treatment, a supplement to treatments that present participants with photos of their group members, subjects may divide their contributions between two different public goods, one of which makes their contributions public. Two findings are of particular interest to this study: (1) if subjects contribute to the public good, they do so via the visible public good, which can be seen as evidence for $\mathrm{C} 1$; and (2) optional reporting increases contributions, which may be interpreted as support for $\mathrm{C} 3$. In contrast, this study differs from Andreoni and Petrie by maintaining a single public good to separate any effects that may derive from having multiple public goods (Corazzini et al. 2013). In addition, there are no opportunities to identify group members so as to mitigate any confounding effects between voluntary disclosure and identification. Finally, this study disentangles the effects of selfselection behavior from that of signaling.

\section{EXPERIMENTAL DESIGN AND HYPOTHESES}

\section{Experimental design}

All experimental treatments utilized the standard VCM design as put forward by Isaac et al. (1984) and described, briefly, above. Parameters have been modified to parallel the experimental studies on information and to ease subsequent comparison of results. The experiment consists of 2 stages that are each 10 rounds long. Stage 1 is the baseline public goods game, which is the same as the "no information" treatment, whereas stage 2 varies across treatments. There are four treatments, each described below. A fifth treatment, in which a vote took place to determine whether or not disclosure would be mandated, was also run. Because this treatment is not central to the present analysis, details and results are not reported. The two-stage design was implemented to detect and account for any group effects. Participants in all treatments were informed about the number of rounds in the experiment.

Participants were randomly assigned into groups of five, i.e., $N$ $=5$. Within these groups, each subject received a subject number (1-5). Participants remained in these groups and retained these subject numbers until the end of the experiment. At the beginning of every round, individuals received 25 tokens, which they were to distribute between an individual fund and a group fund. For every token placed in the individual fund, the individual received $2 \phi$, i.e., $p=2$. For every token he/she placed in the group fund, every member in the group received $1 \phi$, i.e., $G / N=1$. This implies MPCR $=0.5$, which is a commonly used value in the literature (see, for example, Weimann 1994, Croson 2001, Bigoni and Suetens 2012). Once everyone had made a transfer decision, subjects received information, the content of which varied across treatments. Subjects received this information every round and had access to their own contribution information from previous rounds when making their transfer decisions. At the end of the experiment, subjects received the sum of their per-round earnings and a US\$5 show-up payment.

No disclosure (no_discl)

All subjects participated in this treatment as the baseline in the first 10 rounds. Thereafter, subjects who participated in the no_discl treatment participated in another 10 rounds in stage 2. The defining feature of the treatment was that once everyone had made a transfer decision, subjects received information on their own contribution to the group fund, the total contributions to the group fund by the group, and their own earnings for the round. 


\section{Mandatory disclosure (mandatory)}

The mandatory treatment is the same as the baseline information treatment with the exception that at the end of each round participants also received information on the individual transfers made by their group members. This treatment mirrors the full information treatments used by Sell and Wilson (1991) and Croson (2001) to analyze the impact of social information.

Voluntary simultaneous to contribution (vol_sim)

The vol_sim treatment is similar to the no_discl treatment but differs in that, at the time of the contribution decision, subjects were required to also decide whether they wished to reveal the amount of their contribution to their group members. At the end of each round, participants received, along with the information received in the no_discl treatment, information on individual transfers by those group members who chose to reveal their contributions.

Voluntary prior to contribution (vol_before)

The vol_before treatment adds a further step to the vol_sim treatment. Every round, participants decided whether to reveal their contributions to the group fund before making their transfer decisions. Once all participants had decided whether to publicize their transfers, all participants received a message stating how many individuals in the group decided to reveal their contributions. Then subjects decided how to distribute their tokens. The information received at the end of the round was identical to that received in the vol_sim treatment.

\section{Hypotheses}

The hypotheses mirror the general conjectures outlined in the discussion of the literature.

H1. A majority of individuals in the vol_sim and vol_before treatments will choose to disclose their contributions

This assertion is explored by summing the instances when individuals choose to reveal contributions across periods in stage 2. This information is displayed as a percentage of the number of instances an individual could disclose contributions. Logit regression models are used to explore the decision to disclose in these treatments.

\section{H2. Voluntarily revealed contributions are higher}

H2a. Voluntarily public contributions are higher than mandated public contributions

To test this assertion, average contributions in the mandatory treatment are compared to public contributions in the vol_sim and vol_before treatments. To account for confounding effects of group composition and contribution history, this conjecture will be tested in a panel regression model accounting for stage 1 contributions.

H2b. Voluntarily public contributions are higher than voluntarily hidden contributions

This analysis will mirror the analysis for $\mathrm{H} 2 \mathrm{a}$, but will contrast public contributions with hidden contributions in the vol_sim and vol_before treatments.

H3. Group contributions in the voluntary treatments are higher than in the no_discl and mandatory treatments

Stage 2 total contributions to the group fund in the voluntary treatments are contrasted with total contributions in the no_discl and mandatory treatments. Behavior from stage 1 is used to account for any group effects.

\section{H4. Social information leads to greater contributions}

H4a: More social information leads to greater contributions at the group level

More social information is operationalized through the number of individual contribution decisions that are public to the group. Because only the voluntary treatments have variation in social information, data from these are used to assess the role of social information.

H4b. More social information leads to greater contributions at the individual level

Greater group-level contributions with increased social information may be the result of a combination of effects. The first effect is that public contributions are higher (H2); thus, with more public contributions, average contributions will be higher. In addition, individuals who choose to keep contributions hidden may also increase contributions in response to others revealing their contributions. To distinguish between these different effects, data from the vol_sim and vol_before treatments are used and further separated into public and private contributions. Individual contribution decisions are then regressed on the number of other individuals choosing to reveal contributions. If these coefficients are positive and significant, there is evidence that higher group contributions are the result of both effects.

H5. The effect of voluntary disclosure will be more pronounced when signal quality is greater, i.e., when subjects can signal within a period rather than across periods

This hypothesis is tested by comparing group-level contributions across the vol_sim and vol_before treatments. The number of individuals disclosing contributions is controlled to account for group-composition effects.

\section{Experimental implementation}

The computerized experiment was programmed and conducted with the software z-Tree (Fischbacher 2007). Subjects received instructions for each stage via their computer terminal. To ensure common information among participants, subjects received handouts and the experimenter reviewed the instructions publicly. To ensure that participants were comfortable with the decision task, everyone was required to answer a short quiz. Subjects could not advance without answering the quiz questions correctly.

The sessions were conducted at Indiana University in the interdisciplinary experimental lab in 2013. Subjects were recruited from the Indiana University undergraduate population using ORSEE (Online Recruitment System for Economics Experiments). A total of 190 students from various majors participated in the sessions. On average, subjects received US\$20.53 (including a \$5 show-up payment) in experimental sessions that typically lasted about 45 minutes. Table 1 shows the distribution of subjects per treatment.

\section{RESULTS}

\section{General observations}

Corroborating prior public goods experiments, all treatments show greater than zero average contributions (see Fig. 1 and group-level summary statistics in Table 2), and thus contributions 
Table 1. Overview of treatments.

\begin{tabular}{lcccc}
\hline \hline Treatment & Stage 1 & Stage 2 & $\begin{array}{c}\text { Number } \\
\text { of } \\
\text { groups }\end{array}$ & $\begin{array}{c}\text { Number } \\
\text { of } \\
\text { subjects }\end{array}$ \\
\hline No_discl & No information & No_discl & 11 & 55 \\
Mandatory & No information & Mandatory & 11 & 55 \\
Vol_sim & No information & Vol_sim & 7 & 35 \\
Vol_before & No information & Vol_before & 9 & 45 \\
\hline
\end{tabular}

go beyond the Nash prediction. In stage 1, the average contributions rate is $32.24 \%$, which is similar to comparable studies with the same MPCR, such as $33.2 \%$ observed by Andreoni (1988). During stage 2, the average contribution rate increased substantially to $44.38 \%$ with large variations across treatments (rates range between $29.27 \%$ and $58.16 \%$ in stage 2), as shown in Figure 1 and Table 2. A common trend is the increase in group contributions in stage 2 for all treatments, except the no_discl treatment. Total transfers to the group fund actually decreased in that treatment. Using paired t-tests, these changes in contributions across stages prove to be statistically significant (at the $5 \%$ and $10 \%$ levels) for all treatments, suggesting that the social information treatments improve upon the baseline setting in stage 1 .

Fig. 1. Group-level contributions (in percent) to the group fund by treatment.

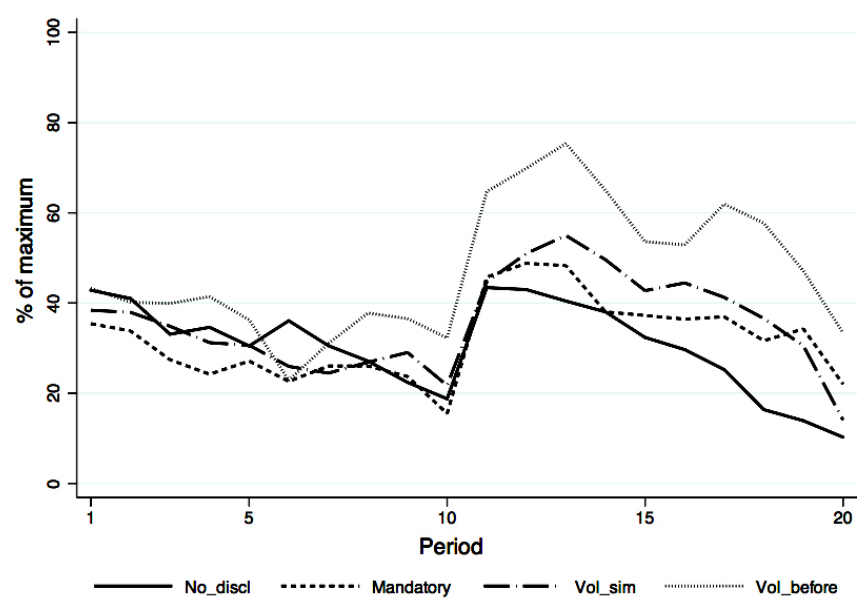

\section{Revisiting hypotheses}

H1. A majority of individuals in the vol_sim and vol_before treatments will choose to disclose their contributions

Given the opportunity to reveal, the majority of individuals chose to do so: $64 \%$ of the opportunities to disclose contributions are used to reveal information in the vol_sim treatment; in the vol_before treatment, the figure is $75 \%$. This suggests that voluntary disclosure policies can be effective in creating transparency. The disclosure decision is studied using panel logit regression with data from the vol_sim and vol_before treatments (Table 3). Models 1-4 use the decision to reveal as the dependent
Table 2. Summary statistics: mean group level contributions by stage and treatment.

\begin{tabular}{|c|c|c|c|c|c|}
\hline \multirow[t]{2}{*}{ Treatment } & \multicolumn{2}{|c|}{ Stage 1} & \multicolumn{2}{|c|}{ Stage 2} & \multirow[b]{2}{*}{ Difference } \\
\hline & $\begin{array}{c}\text { \# of tokens } \\
\text { (standard } \\
\text { deviation) }\end{array}$ & $\begin{array}{l}\% \text { of } \\
\max \end{array}$ & $\begin{array}{c}\text { \# of tokens } \\
\text { (standard } \\
\text { deviation) }\end{array}$ & $\begin{array}{l}\% \text { of } \\
\max \end{array}$ & \\
\hline No_discl & $\begin{array}{c}396.18 \\
(227.84)\end{array}$ & $31.69 \%$ & $\begin{array}{c}365.82 \\
(203.14)\end{array}$ & $29.27 \%$ & $-2.42 \%$ \\
\hline Mandatory & $\begin{array}{c}327.36 \\
(117.85)\end{array}$ & $26.19 \%$ & $\begin{array}{c}474.27 \\
(327.01)\end{array}$ & $37.94 \%$ & $11.75 \% *$ \\
\hline Vol_sim & $\begin{array}{c}376.29 \\
(151.09)\end{array}$ & $30.10 \%$ & $\begin{array}{c}512.29 \\
(275.21)\end{array}$ & $40.98 \%$ & $10.88 \% * *$ \\
\hline Vol_before & $\begin{array}{c}451.89 \\
(156.97) \\
\end{array}$ & $36.15 \%$ & $\begin{array}{c}727 \\
(292.25) \\
\end{array}$ & $58.16 \%$ & $22.01 \% * * *$ \\
\hline
\end{tabular}

variable. Models 1-3 explore the decisions in periods 12-20, whereas model 4 examines the first disclosure decisions (in period 11) when no feedback about others' disclosure decision is available. The models test for differences in behavior across vol_sim and vol_before by including a dummy variable for vol_before. In addition, they include variables for how many others in the group are revealing their contributions and how much others, who have disclosed their behavior, are contributing. Both are lagged to reflect the information available to subjects when they make their own disclosure decision. Further, these lagged variables are interacted with the vol_before dummy to test for differences in behavior in response to this information across the two voluntary treatments. Model 2 also includes an individual's decision in the prior period, and model 3 further includes the individual's contribution to the group fund in period 1 , as a proxy for behavioral type. In these three models, there is no significant difference between how individuals make disclosure decisions between the two treatments. Individuals seem to exhibit reciprocal behavior; they are more likely to reveal their contribution if others have done so in the past. Further, once an individual has made the decision to disclose, she is more likely to continue to do so. Finally, model 3 indicates that more generous individuals, as measured by period 1 contributions, are also more likely to reveal their contributions. Exploring behavior in period 11 , it is evident that any difference in disclosure decisions between vol_sim and vol_before arises largely from the initial decision in period 11.

\section{$H 2 a$ and H2b. Voluntarily public contributions are higher than mandated public contributions and voluntarily hidden}

contributions, respectively

Figure 2 displays the private contributions, combined contributions, and public contributions across the four treatments as well as standard error bars. There is a dramatic difference between voluntarily hidden contributions and voluntarily revealed contributions, leading to visible average contributions being significantly higher than actual average contributions. In addition, the voluntarily disclosed contributions in both the vol_sim and vol_before are significantly higher than public contributions in the mandatory treatment. To further explore this, examine the random effects model and the pooled Tobit model 
Table 3. Panel logit regression on the decision to reveal contributions.

\begin{tabular}{|c|c|c|c|c|}
\hline & (1) & (2) & (3) & (4) \\
\hline Constant & $\begin{array}{c}0.233 \\
(0.853)\end{array}$ & $\begin{array}{l}-0.319 \\
(0.793)\end{array}$ & $\begin{array}{l}-2.190^{*} \\
(0.068)\end{array}$ & $\begin{array}{c}-1.06^{* * * *} \\
(0.001)\end{array}$ \\
\hline Vol_before dummy & $\begin{array}{l}1.381 \\
(0.416)\end{array}$ & $\begin{array}{c}0.906 \\
(0.575)\end{array}$ & $\begin{array}{c}0.607 \\
(0.689)\end{array}$ & $\begin{array}{l}1.25^{* * *} \\
(0.005)\end{array}$ \\
\hline Lagged other reveal & $\begin{array}{l}0.524^{*} \\
(0.081)\end{array}$ & $\begin{array}{l}0.513^{*} \\
(0.079)\end{array}$ & $\begin{array}{l}0.539^{*} \\
(0.062)\end{array}$ & \\
\hline $\begin{array}{l}\text { Lagged other reveal } \\
\text { x vol_before }\end{array}$ & $\begin{array}{l}-0.0963 \\
(0.803)\end{array}$ & $\begin{array}{l}-0.0384 \\
(0.919)\end{array}$ & $\begin{array}{l}-0.0262 \\
(0.944)\end{array}$ & \\
\hline $\begin{array}{l}\text { Lagged average } \\
\text { other contributions }\end{array}$ & $\begin{array}{l}0.0452 \\
(0.310)\end{array}$ & $\begin{array}{l}0.0400 \\
(0.345)\end{array}$ & $\begin{array}{l}0.0397 \\
(0.325)\end{array}$ & \\
\hline $\begin{array}{l}\text { Lagged average } \\
\text { other contributions } \\
\text { x vol_before }\end{array}$ & $\begin{array}{l}-0.0132 \\
(0.824)\end{array}$ & $\begin{array}{c}-0.00532 \\
(0.926)\end{array}$ & $\begin{array}{c}-0.00820 \\
(0.882)\end{array}$ & \\
\hline $\begin{array}{l}\text { Prior period's } \\
\text { decision }\end{array}$ & & $\begin{array}{l}0.676^{*} \\
(0.073)\end{array}$ & $\begin{array}{l}0.648^{*} \\
(0.082)\end{array}$ & \\
\hline $\begin{array}{l}\text { Contribution in } \\
\text { period } 1\end{array}$ & & & $\begin{array}{c}0.191 * * * \\
(0.000)\end{array}$ & $\begin{array}{r}0.21^{* * *} \\
(0.000)\end{array}$ \\
\hline Periods included: & $12-20$ & $12-20$ & $12-20$ & 11 \\
\hline Observations & 715 & 715 & 715 & 80 \\
\hline \multicolumn{5}{|c|}{$\begin{array}{l}* \mathrm{p}<0.1, * * \mathrm{p}<0.05, * * * \mathrm{p}<0.01, \mathrm{P} \text {-values in parantheses. } \\
\text { Dummies for periods were included in the regressions but omitted in } \\
\text { table. }\end{array}$} \\
\hline
\end{tabular}

Fig. 2. Average private, combined, and public individual contributions across treatments.

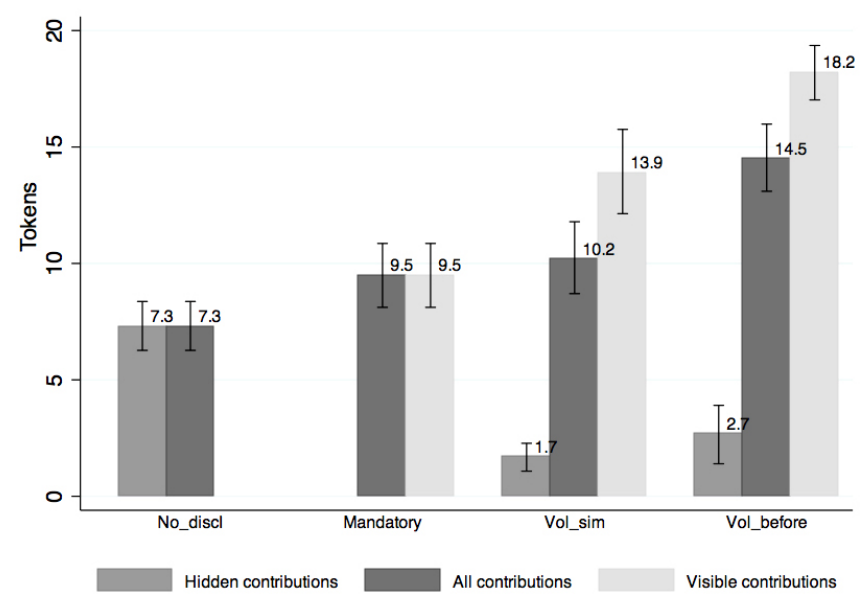

in Table 4. The independent variables are (1) a dummy variable for the mandatory treatment; (2) two dummy variables for public contributions, one for the vol_sim treatment and one for the vol_before treatment; and (3) two dummy variables for hidden contributions in the two voluntary treatments. Both models
Table 4. Regression analyses of individual level contributions given public and private contributions.

\begin{tabular}{|c|c|c|}
\hline & $\begin{array}{l}(5) \\
\mathrm{RE}\end{array}$ & $\begin{array}{c}(6) \\
\text { Tobit }\end{array}$ \\
\hline Constant & $\begin{array}{c}2.03 \\
(0.421)\end{array}$ & $\begin{array}{c}-3.46 \\
(0.201)\end{array}$ \\
\hline Mandatory & $\begin{array}{c}3.12 \\
(0.156)\end{array}$ & $\begin{array}{l}5.701 * * \\
(0.014)\end{array}$ \\
\hline Public (vol_sim) & $\begin{array}{l}6.87 * * * \\
(0.000)\end{array}$ & $\begin{array}{c}11.82 * * * \\
(0.000)\end{array}$ \\
\hline Private (vol_sim) & $\begin{array}{c}-3.40 * * * \\
(0.007)\end{array}$ & $\begin{array}{c}-10.26 * * * \\
(0.001)\end{array}$ \\
\hline Public (vol_before) & $\begin{array}{l}9.40 * * * \\
(0.000)\end{array}$ & $\begin{array}{l}18.25 * * * \\
(0.000)\end{array}$ \\
\hline Private (vol_before) & $\begin{array}{l}-2.32 \\
(0.119)\end{array}$ & $\begin{array}{c}-13.04 * * * \\
(0.000)\end{array}$ \\
\hline $\begin{array}{l}\text { Average group contributions in } \\
\text { stage } 1 \text { (averaged over } 10 \text { periods) }\end{array}$ & $\begin{array}{l}0.14 * * * \\
(0.001)\end{array}$ & $\begin{array}{l}0.27 * * * \\
(0.000)\end{array}$ \\
\hline Periods included: & $11-20$ & $11-20$ \\
\hline $\begin{array}{l}\text { R-sq: } \\
\text { Within } \\
\text { Between } \\
\text { Overall }\end{array}$ & $\begin{array}{l}0.2543 \\
0.4468 \\
0.3643\end{array}$ & \\
\hline Observations: & 1900 & 1900 \\
\hline $\begin{array}{l}\text { Left-censored } \\
\text { Uncensored } \\
\text { Right-censored }\end{array}$ & & $\begin{array}{l}620 \\
912 \\
368\end{array}$ \\
\hline \multicolumn{3}{|c|}{$\begin{array}{l}* \mathrm{p}<0.1, * * \mathrm{p}<0.05, * * * \mathrm{p}<0.01, \mathrm{P} \text {-values in parentheses. } \\
\text { Random effects models use errors clustered at the group-level. } \\
\text { Tobit model errors clustered at the subject-level. Lower limit }=0 \text {, upper } \\
\text { limit }=25 \\
\text { Dummies for rounds were included in the regressions but omitted in } \\
\text { table. }\end{array}$} \\
\hline
\end{tabular}

include a variable to control for group history in stage 1, i.e., total group contributions in stage 1 averaged across periods. In both models, both the public and private contributions are significantly different from the contributions in the no_discl treatment. Contributions in the mandatory treatment are not significantly higher in model 5, but given the number of censored contributions, the Tobit model may be the better specification. In this model, mandatory contributions are significantly higher than in the no_discl treatment. Paired significance tests of the coefficients in the Tobit model indicate that all contribution levels are significantly different (at the $1 \%$ level) except for the private contributions in vol_sim and vol_before. Therefore, both $\mathrm{H} 2 \mathrm{a}$ and $\mathrm{H} 2 \mathrm{~b}$ are supported.

H3. Group contributions in the voluntary treatments are higher than in the no_discl and mandatory treatments

Returning to Table 2, group-level contributions in stage 2 across treatments are compared; there are no significant differences in stage 1 contributions across the different treatments. Using 
Wilcoxon-Mann-Whitney tests, it is found that only the vol_before treatment results in group contributions are significantly higher than those in the no_discl (p-value 0.0109) treatment. Contributions in this treatment are also significantly higher than in the mandatory treatment (at the 5\% level). This implies that the ability to signal, rather than to voluntarily reveal contributions, improves cooperation. This is further explored below.

\section{H4a. More social information leads to greater contributions at} the group level

The regression models in Table 5 use data from vol_sim and vol_before. Both a random effects and a pooled Tobit model (models 7 and 8 ) are run for contributions at the group level. The main variable of interest here is number_revealed, which ranges from 0 to 5 depending on how many members of a group decided to reveal their contributions. Both models indicate that number_revealed is positive and significant, which suggests that more social information leads to higher contributions at the group level. But, as indicated above, this finding may be the result of two separate effects. Hence, individual contribution decisions must be considered.

Table 5. Regression analysis of group-level contributions in voluntary treatments.

\begin{tabular}{|c|c|c|}
\hline & $\begin{array}{l}(7) \\
\mathrm{RE}\end{array}$ & $\begin{array}{c}(8) \\
\text { Tobit }\end{array}$ \\
\hline Constant & $\begin{array}{l}0 \\
(.)\end{array}$ & $\begin{array}{l}-23.39 * \\
(0.055)\end{array}$ \\
\hline Vol_before dummy & $\begin{array}{c}-5.42 \\
(0.643)\end{array}$ & $\begin{array}{l}-13.72 \\
(0.424)\end{array}$ \\
\hline Number_reveal & $\begin{array}{l}9.13 * * * \\
(0.000)\end{array}$ & $\begin{array}{c}14.75 * * * \\
(0.000)\end{array}$ \\
\hline Vol_before x number_reveal & $\begin{array}{c}4.33 \\
(0.192)\end{array}$ & $\begin{array}{c}6.34 \\
(0.196)\end{array}$ \\
\hline $\begin{array}{l}\text { Average group contributions in } \\
\text { stage } 1 \text { (averaged over } 10 \text { periods) }\end{array}$ & $\begin{array}{c}0.079 * * \\
(0.013)\end{array}$ & $\begin{array}{c}0.074 * * * \\
(0.007)\end{array}$ \\
\hline Periods included: & $11-20$ & $11-20$ \\
\hline $\begin{array}{l}\text { R-sq: } \\
\text { Within } \\
\text { Between } \\
\text { Overall }\end{array}$ & $\begin{array}{l}0.5987 \\
0.7561 \\
0.6947\end{array}$ & \\
\hline Observations: & 160 & 160 \\
\hline $\begin{array}{l}\text { Left-censored } \\
\text { Uncensored } \\
\text { Right-censored }\end{array}$ & & $\begin{array}{c}3 \\
148 \\
9\end{array}$ \\
\hline \multicolumn{3}{|c|}{$\begin{array}{l}* \mathrm{p}<0.1, * * \mathrm{p}<0.05, * * * \mathrm{p}<0.01, \mathrm{P} \text {-values in parentheses. } \\
\text { Dummies for rounds were included in the regressions but omitted in } \\
\text { table. } \\
\text { Random effects and Tobit models with errors clustered at the group } \\
\text { level. } \\
\text { Tobit model - lower limit }=0 \text {, upper limit }=125\end{array}$} \\
\hline
\end{tabular}

H4b. More social information leads to greater contributions at the individual level

The models in Table 6 explore the effect of social information at the individual level. Separate models are run for the two voluntary treatments to account for possible different mechanisms in play because of the timing of social information being transmitted. Both random effects estimations and pooled Tobit models were used. The following variables were used to distinguish between the effects of information content and information amount: (1) public contribution indicates whether the contribution that was made was voluntarily revealed; (2) lagged average of visible contributions made by others, i.e., a proxy for information content; (3) lagged average other visible contributions interacted with public contribution, to asses whether individuals utilized this information differently depending on their disclosure decision; (4) number of others choosing to reveal, i.e., a proxy for the amount of social information (lagged in vol_sim case given that these subjects did not know how many others would reveal their contribution before making their current round contribution decision); (5) number of others revealing interacted with public contributions (also lagged for vol_sim); and (6) average contributions made in stage 1 , to account for group effects.

The main finding in these models is that the amount of social information (i.e., how many others disclose contributions) does not significantly affect contributions, but the informational content (i.e., how much others are contributing) does. Further, individuals in the vol_sim treatment, whether they disclosed contributions or not, were swayed by the contributions made by others. Meanwhile, in the vol_before treatment, only individuals who revealed their contributions made their contributions dependent on visible contributions by others.

Finally, consider models 13-16 (Table 7). These random effects models explore contribution changes in the vol_sim (models 13 and 14) and vol_before (models 15 and 16) treatments. They are used to examine convergence behavior toward the mean as is observed in the field studies discussed above. Models 13 and 15 use data only from public contributions, and models 14 and 16 use data from hidden contributions to account for different mechanisms at play. The following variables are included: (1) difference between last period's average visible contributions made by others and the individual's own contributions, (positive if the individual's contribution was less than the average); (2) a dummy variable equal to 1 when an individual contributed more than the visible average and 0 otherwise; and (3) an interaction between these two variables.

A positive coefficient on the first variable implies convergence behavior. The second and third variables explore differences in convergence behavior based on individuals being high contributors. In all four models, individuals converge toward the mean. This occurs irrespective of whether the individual decided to disclose contributions. Thus, low contributors increase contributions and high contributors lower their contributions in response to social information, the latter being the boomerang effect. However, in the vol_before treatment, individuals who disclose their contributions seem to exhibit a weaker boomerang effect, even though their convergence behavior does not change. This may indicate that improved opportunities to reciprocate behavior may help attenuate the boomerang effect. 
Table 6. Regression analyses of individual level contributions in voluntary treatments.

\begin{tabular}{|c|c|c|c|c|}
\hline & \multicolumn{2}{|c|}{ Vol_sim } & \multicolumn{2}{|c|}{ Vol_before } \\
\hline & $\begin{array}{l}(9) \\
\mathrm{RE}\end{array}$ & $\begin{array}{l}(10) \\
\text { Tobit }\end{array}$ & $\begin{array}{l}(11) \\
\mathrm{RE}\end{array}$ & $\begin{array}{l}(12) \\
\text { Tobit }\end{array}$ \\
\hline Constant & $\begin{array}{c}-6.23 * * * \\
(0.000)\end{array}$ & $\begin{array}{l}-17.52^{* * *} \\
(0.000)\end{array}$ & $\begin{array}{c}1.44 \\
(0.636)\end{array}$ & $\begin{array}{c}-23.39 * * * \\
(0.006)\end{array}$ \\
\hline Public contribution & $\begin{array}{l}9.99 * * * \\
(0.000)\end{array}$ & $\begin{array}{c}15.87 * * * \\
(0.000)\end{array}$ & $\begin{array}{c}9.40^{* * * *} \\
(0.000)\end{array}$ & $\begin{array}{c}18.47 * * * \\
(0.030)\end{array}$ \\
\hline $\begin{array}{l}\text { Lagged average visible } \\
\text { contribution by others }\end{array}$ & $\begin{array}{l}0.26^{* *} \\
(0.024)\end{array}$ & $\begin{array}{l}0.61^{* *} \\
(0.017)\end{array}$ & $\begin{array}{c}0.08 \\
(0.402)\end{array}$ & $\begin{array}{c}0.24 \\
(0.386)\end{array}$ \\
\hline $\begin{array}{l}\text { Lagged average visible } \\
\text { contribution by others } x \text { public } \\
\text { contribution }\end{array}$ & $\begin{array}{c}0.10 \\
(0.436)\end{array}$ & $\begin{array}{c}0.14 \\
(0.585)\end{array}$ & $\begin{array}{c}0.14 * * * \\
(0.005)\end{array}$ & $\begin{array}{c}0.56 * * * \\
(0.000)\end{array}$ \\
\hline (Lagged) number_reveal & $\begin{array}{c}0.68 \\
(0.455)\end{array}$ & $\begin{array}{c}0.08 \\
(0.946)\end{array}$ & $\begin{array}{c}-0.54 \\
(0.205)\end{array}$ & $\begin{array}{c}-0.65 \\
(0.796)\end{array}$ \\
\hline $\begin{array}{l}\text { (Lagged) number_reveal x } \\
\text { public contribution }\end{array}$ & $\begin{array}{c}0.29 \\
(0.690)\end{array}$ & $\begin{array}{c}0.47 \\
(0.710)\end{array}$ & $\begin{array}{c}1.02 \\
(0.208)\end{array}$ & $\begin{array}{c}3.36 \\
(0.257)\end{array}$ \\
\hline $\begin{array}{l}\text { Average group contributions in } \\
\text { stage } 1 \text { (averaged over } 10 \\
\text { periods) }\end{array}$ & $\begin{array}{c}0.11^{*} \\
(0.050)\end{array}$ & $\begin{array}{c}0.16 \\
(0.112)\end{array}$ & $\begin{array}{c}0.08 \\
(0.199)\end{array}$ & $\begin{array}{c}0.22 * \\
(0.073)\end{array}$ \\
\hline $\begin{array}{l}\text { R-sq: } \\
\text { Within } \\
\text { Between } \\
\text { Overall }\end{array}$ & $\begin{array}{l}0.5311 \\
0.7343 \\
0.6544\end{array}$ & & $\begin{array}{l}0.3625 \\
0.7948 \\
0.5929\end{array}$ & \\
\hline Observations: & 313 & 313 & 402 & 402 \\
\hline $\begin{array}{l}\text { Left-censored } \\
\text { Uncensored } \\
\text { Right-censored }\end{array}$ & & $\begin{array}{c}102 \\
170 \\
41\end{array}$ & & $\begin{array}{l}107 \\
139 \\
156\end{array}$ \\
\hline $\begin{array}{l}* \mathrm{p}<0.1, * * \mathrm{p}<0.05, * * * \mathrm{p}<0 \\
\text { Standard errors are in parenthe } \\
\text { Random effects models use erro } \\
\text { Tobit model errors clustered at } \\
25\end{array}$ & e subject & $\begin{array}{l}\text { at the gro } \\
\text { evel. Lowe }\end{array}$ & $\begin{array}{l}\text {-level. } \\
\text { imit }=0 \text {, }\end{array}$ & er limit = \\
\hline
\end{tabular}

H5. The effect of voluntary disclosure will be more pronounced when signal quality is greater

Finally, once the number of public contributions is accounted for, there is no significant difference in contribution behavior at the group level between vol_sim and vol_before (Table 5). Higher contributions in the vol_before treatment (Table 2) are thus an artifact of higher disclosure rates (see discussion for $\mathrm{H} 1$ ) given that public contributions are higher than private contributions (Table 4). Therefore, higher signal quality leads to greater transparency, which in turn leads to greater contributions.

\section{CONCLUSION AND DISCUSSION}

The experiment presented allows the testing of the impact of voluntary information disclosure in a linear public goods setting. The treatments have been designed to assess the impact of voluntary disclosure of contributions on contribution levels. In addition, the design allows one to distinguish between the impact of voluntary disclosure of contribution decisions (and the scrutiny this entails) and the impact of signaling to other group members one's willingness to cooperate.
Table 7. Regression analyses of change in individual level contributions in voluntary treatments.

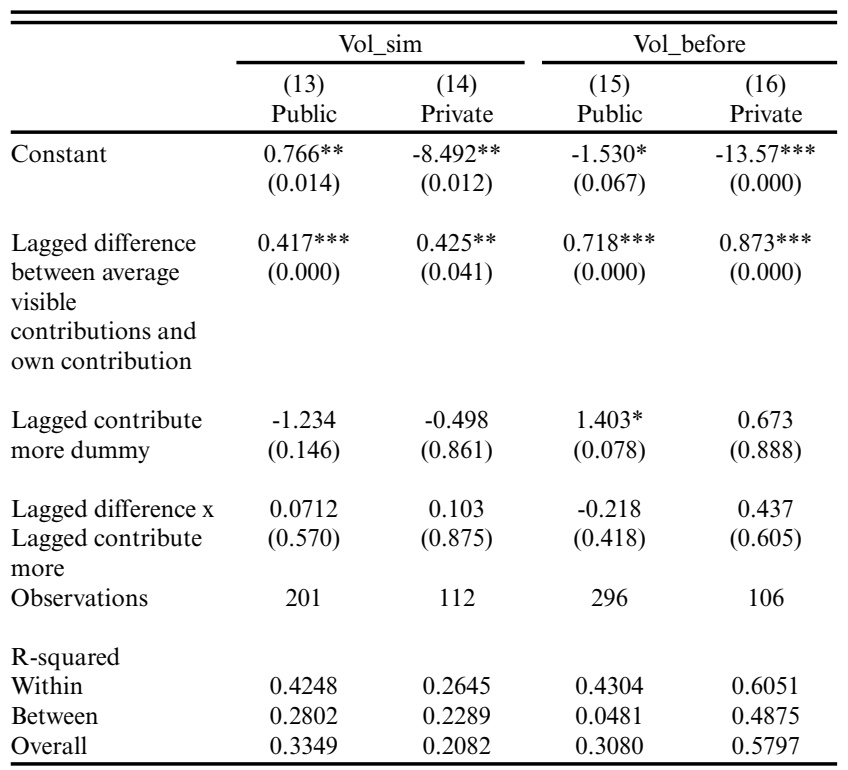

$* \mathrm{p}<0.1, * * \mathrm{p}<0.05, * * * \mathrm{p}<0.01$

Standard errors are in parentheses.

Random effects models use errors clustered at the group level.

There are several main findings of this experiment. First, given the opportunity, individuals choose to reveal their contributions more often than not. Those individuals who do reveal their transfers to the group fund contribute significantly more to the group than individuals who keep their contributions hidden. Second, greater information leads to higher cooperation at the group level. This effect is particularly pronounced when individuals are able to voluntarily reveal contributions, as compared to having this disclosure mandated. This means that, in the two voluntary conditions, as more individuals make their contributions public, group contributions increase. In contrast to Weimann (1994), Wilson and Sell (1997), and Croson (2001), it was found that providing subjects with full information on individual contribution decisions significantly increased contribution levels, although this is dependent on model specification. This may result from the structure of the experiment, given that the design utilized had all subjects participate in the no_discl treatment in the first 10 rounds. However, this design is key in determining whether there are any group effects that may cause one to over- or under-state effects. Finally, the most important factor in improving cooperation in these experiments seems to be signal quality, or the inclusion of a message informing individuals of how many other group members volunteered to reveal their contributions. This form of signaling led to the largest contributions to the public good. This highlights the potential for future research to explore the boundaries of using signaling to improve cooperation in social dilemmas.

Although experimental results by themselves, in particular lab experimental results (Levitt and List 2007), are not a sufficient basis to design or justify policy measures, they may be used to 
highlight behavioral tendencies and focus additional policyrelevant research. In light of this, the results have several implications for policy. The level at which information was provided in the endogenous disclosure treatments indicates that voluntary disclosure policies can result in transparency without requiring external enforcement measures. Hence, when enforcement is prohibitively costly, a voluntary disclosure policy may be more efficient. Furthermore, contributions that are voluntarily kept private are more likely to be lower than those that are made public. As a result, if actors have the ability to mask free-riding behavior, reciprocators are less likely to respond with uncooperative behavior because the observable average contribution rate is higher than when free riders are mandated to disclose their contributions. This may indicate that voluntary disclosure measures may be particularly effective in environments with numerous free riders. In other words, free riding is more deleterious to cooperation when others can observe it. On this basis, it is clear that voluntary disclosure policies may be useful tools, and further research is necessary regarding the conditions under which these may be more or less effective.

Responses to this article can be read online at: http://www.ecologyandsociety.org/issues/responses. php/8004

\section{Acknowledgments:}

I gratefully acknowledge financial support from the National Science Foundation (SES-0849551). I thank James Walker and Brock Stoddard for their feedback and guidance. I also thank participants at the Vincent and Elinor Ostrom Workshop in the Political Theory and Policy Analysis colloquia and two anonymous reviewers for their helpful comments.

\section{LITERATURE CITED}

Allcott, H. 2011. Social norms and energy conservation. Journal of Public Economics 95:1082-1095. http://dx.doi.org/10.1016/j. jpubeco.2011.03.003

Andreoni, J. 1988. Why free ride? Strategies and learning in public goods experiments. Journal of Public Economics 37:291-304. http://dx.doi.org/10.1016/0047-2727(88)90043-6

Andreoni, J., and R. Petrie. 2004. Public goods experiments without confidentiality: a glimpse into fund-raising. Journal of Public Economics 88:1605-1623. http://dx.doi.org/10.1016/ $\underline{\mathrm{s} 0047-2727(03) 00040-9}$

Ayres, I., S. Raseman, and A. Shih. 2013. Evidence from two large field experiments that peer comparison feedback can reduce residential energy usage. Journal of Law, Economics, and Organization 29(5):992-1022. http://dx.doi.org/10.1093/jleo/ $\underline{\text { ews } 020}$

Bao, J., and B. Ho. 2015. Heterogeneous effects of informational nudges on pro-social behavior. BE Journal of Economic Analysis and Policy 15(4):1619-1655

Bigoni, M., and S. Suetens. 2012. Feedback and dynamics in public good experiments. Journal of Economic Behavior and Organization 82:86-95. http://dx.doi.org/10.1016/j.jebo.2011.12.013
Botelho, A., G. W. Harrison, L. M. Costa Pinto, and E. E. Rutström. 2005. Social norms and social choice. Working paper. College of Business, University of Central Florida, Orlando, Florida, USA.

Chaudhuri, A. 2011. Sustaining cooperation in laboratory public goods experiments: a selective survey of the literature. Experimental Economics 14:47-83. http://dx.doi.org/10.1007/ s10683-010-9257-1

Cialdini, R. B., L. J. Demaine, B. J. Sagarin, D. W. Barrett, K. Rhoads, and P. L. Winter. 2006. Managing social norms for persuasive impact. Social Influence 1(1):3-15. http://dx.doi. org/10.1080/15534510500181459

Cialdini, R. B., R. R. Reno, and C. A. Kallgren. 1990. A focus theory of normative conduct: recycling the concept of norms to reduce littering in public places. Journal of Personality and Social Psychology 58(6):1015-1026. http://dx.doi.org/10.1037/0022-3514.58.6.1015

Clark, J. 2002. Recognizing large donations to public goods: an experimental test. Managerial and Decision Economics 23 (1):33-44. http://dx.doi.org/10.1002/mde.1044

Corazzini, L., C. Cotton, and P. Valbonesi. 2013. Too many charities? Insight from an experiment with multiple public goods and contribution thresholds. Working Paper. University of Padua, Padova, Italy. http://dx.doi.org/10.2139/ssrn.2307154

Croson, R. 2001. Feedback in voluntary contribution mechanisms: an experiment in team production. Research in Experimental Economics 8:85-97. http://dx.doi.org/10.1016/ S0193-2306(01)08005-X

Croson, R., and J. Shang. 2008. The impact of downward social information on contribution decisions. Experimental Economics 11(3):221-233. http://dx.doi.org/10.1007/s10683-007-9191-z

Croson, R., and J. Shang. 2013. Limits of the effect of social informaiton on the voluntary provision of public goods: evidence from field experiments. Economic Inquiry 51(1):473-477. http:// dx.doi.org/10.1111/j.1465-7295.2012.00468.x

Ferraro, P. J., and M. K. Price. 2013. Using nonpecuniary strategies to influence behavior: evidence from a large-scale field experiment. Review of Economics and Statistics 95(1):64-73. http://dx.doi.org/10.1162/rest a 00344

Fischbacher, U. 2007. Z-Tree: Zurich toolbox for ready-made economic experiments. Experimental Economics 10(2):171-178. http://dx.doi.org/10.1007/s10683-006-9159-4

Fischer, C. 2008. Feedback on household electricity consumption: a tool for saving energy? Energy Efficiency 1:79-104. http://dx. doi.org/10.1007/s12053-008-9009-7

Goldstein, N. J., R. B. Cialdini, and V. Griskevicius. 2008. A room with a viewpoint: using social norms to motivate environmental conservation in hotels. Journal of Consumer Research 35 (3):472-482. http://dx.doi.org/10.1086/586910

Hamman, J. R., R. A. Weber, and J. Woon. 2011. An experimental investigation of electoral delegation and the provision of public goods. American Journal of Political Science 55(4):738-752. http:// dx.doi.org/10.1111/j.1540-5907.2011.00531.x 
Isaac, R. M., D. Schmidtz, and J. M. Walker. 1989. The assurance problem in a laboratory market. Public choice 62(3):217-236. http://dx.doi.org/10.1007/bf02337743

Isaac, R. M., J. M. Walker, and S. H. Thomas. 1984. Divergent evidence on free riding: an experimental examination of possible explanations. Public Choice 43:113-149. http://dx.doi.org/10.1007/ BF00140829

Isaac, R. M., J. M. Walker, and A. W. Williams. 1994. Group size and the voluntary provision of public goods: experimental evidence utilizing large groups. Journal of Public Economics 54:1-36. http://dx.doi.org/10.1016/0047-2727(94)90068-X

Johnson, E. J., S. B. Shu, B. G. Dellaert, C. Fox, D. G. Goldstein, G. Häubl, R. P. Larrick, J. W. Payne, E. Peters, D. Schkade, B. Wansink, and E. U. Weber. 2012. Beyond nudges: tools of a choice architecture. Marketing Letters 23(2):487-504. http://dx.doi. org/10.1007/s11002-012-9186-1

Jones, M., and M. McKee. 2004. Feedback information and contributions to not-for-profit enterprises: experimental investigations and implications for large-scale fund-raising. Public Finance Review 32(5):512-527. http://dx.doi. org/10.1177/1091142104267064

Kosfeld, M., A. Okada, and A. Riedl. 2009. Institution formation in public goods games. American Economic Review 99:1335-1355. http://dx.doi.org/10.1257/aer.99.4.1335

Kreps, D. M., P. Milgrom, J. Roberts, and R. Wilson. 1982. Rational cooperation in the finitely-repeated prisoners' dilemma. Journal of Economic Theory 27:245-252 http://dx.doi. org/10.1016/0022-0531(82)90029-1

Kroll, S., T. L. Cherry, and J. F. Shogren. 2007. Voting, punishment, and public goods. Economic Inquiry 45(3):557-570. http://dx.doi.org/10.1111/j.1465-7295.2007.00028.x

Ledyard, J. O. 1995. "Public goods: a survey of experimental research." Pages 111-194 in J. H. Kagel and A. E. Roth, editors. The handbook of experimental economics. Princeton University Press, Princeton, New Jersey, USA.

Levitt, S. D., and J. A. List. 2007. What do laboratory experiments measuring social preferences reveal about the real world? Journal of Economic Perspectives 21:153-174. http://dx.doi.org/10.1257/ jep.21.2.153

McDonald, R. I., and C. S. Crandall. 2015. Social norms and social influence. Current Opinion in Behavioral Sciences 3:147-151. http://dx.doi.org/10.1016/j.cobeha.2015.04.006

Ostrom, E. 2003. "Toward a behavioral theory linking trust, reciprocity, and reputation." Pages 19-79 in E. Ostrom and J. Walker, editors. Trust and reciprocity: interdisciplinary lessons from experimental research. Russell Sage Foundation, New York, New York, USA.

Runge, C. F. 1984. Institutions and the free rider: the assurance problem in collective action. Journal of Politics 46(1):154-181. http://dx.doi.org/10.2307/2130438
Schultz, P. W. 1999. Changing behavior with normative feedback interventions: a field experiment on curbside recycling. Basic and Applied Social Psychology 21(1):25-36. http://dx.doi.org/10.1207/ s15324834basp2101_3

Schultz, P. W., J. M. Nolan, R. B. Cialdini, N. J. Goldstein, and V. Griskevicius. 2007. The constructive, destructive, and reconstructive power of social norms. Psychological Science 18 (5):429-434. http://dx.doi.org/10.1111/j.1467-9280.2007.01917.x

Sell, J., and R. K. Wilson. 1991. Levels of information and contributions to public goods. Social Forces 70(1):107-124. http:// dx.doi.org/10.2307/2580064

Shang, J., and R. Croson. 2009. A field experiment in charitable contribution: the impact of social information on the voluntary provision of public goods. Economic Journal 119:1422-1439. http://dx.doi.org/10.1111/j.1468-0297.2009.02267.x

Sutter, M., S. Haigner, and M. G. Kocher. 2010. Choosing the carrot or the stick? Endogenous institutional choice in social dilemma situations. Review of Economic Studies 77(4):1540-1566. http://dx.doi.org/10.1111/j.1467-937x.2010.00608.x

Thaler, R. H., and C. R. Sunstein. 2008. Nudge: improving decisions about health, wealth, and happiness. Yale University Press, New Haven, Connecticut, USA.

Weimann, J. 1994. Individual behaviour in a free riding experiment. Journal of Public Economics 54(2):185-200. http://dx. doi.org/10.1016/0047-2727(94)90059-0

Wilson, R. K., and J. Sell. 1997. "Liar, liar...”: cheap talk and reputation in repeated public goods settings. Journal of Conflict Resolution 41(5):695-717.

Zelmer, J. 2003. Linear public goods experiments: a meta-analysis. Experimental Economics 6:299-310. http://dx.doi.org/10.1023/ A:1026277420119 